\title{
Foundation and medical training posts will rotate in August
}

\section{Abi Rimmer}

The BMJ

Health Education England (HEE) has announced that all trainees in foundation training and core medical training posts will rotate as usual at the start of August. Planned rotations have been cancelled for May, June, and July as a result of covid-19. ${ }^{2}$

The announcement means that, in England, 19 medical specialties involving over 40000 trainees will rotate in August. The start dates for other specialty training programmes vary across specialties and geographies. HEE said that, as a result of covid-19, more programmes would now have start dates later than August.

HEE said that it would provide trainees and employers with notice of the August and other summer start dates as soon as possible but no later than eight weeks before the intended start date. It added that it was working with the devolved nations, the General Medical Council, and medical royal colleges to enable trainees to progress in their training by increasing the flexibility of training programmes.

Guidance is being developed for trainees and trainers to inform progression decisions being made by annual review of competency progression (ARCP) panels, HEE said.

Sheona Macleod, acting medical director at HEE, said that the organisation wanted to minimise any disadvantages for trainees and provide certainty by giving as much notification as possible so that they had time to plan.

She said, "Our priorities are to protect the education and training of our future workforce, to enable junior doctors and other staff to ensure the continued delivery of healthcare services and to maintain the quality and safety of patient care during a summer period that is likely to be busier than usual."

She added that HEE offices would work with relevant colleagues locally to determine the pace and timing of rotational changes for existing trainees. "The distance travelled by rotating trainees has been reducing over recent years, and HEE has supported moves to minimise change and disruption for individuals," she said.

HEE has arranged a webinar open to all trainees to discuss these issues at $7 \mathrm{pm}$ on Tuesday 26 May. See https://www.hee.nhs.uk/coronavirus-information-trainees.

Seven days in medicine: 15-21 April 2020. BMJ 2020;369:m1569.32327418 2 Rimmer A. Covid-19: Health Education England shares advice for trainees. BMJ 2020;369:m1635. 10.1136/bmj.m1635 32332033

Published by the BMJ Publishing Group Limited. For permission to use (where not already granted under a licence) please go to http://group.bmj.com/group/rights-licensing/ permissions 